\title{
The Effect of Changes in Microscopic Structures on Coke Strength in Carbonization Process
}

\author{
Kenichi HIRAKI, ${ }^{11}$ Hideyuki HAYASHIZAKI, ${ }^{1)}$ Yoshiaki YAMAZAKI, ${ }^{11}$ Tetsuya KANAI, ${ }^{11}$ Xiaoqing ZHANG, ${ }^{1)}$ \\ Masakazu SHOJI, ${ }^{1)}$ Hideyuki AOKI, ${ }^{1)}$ Takatoshi MIURA ${ }^{1)}$ and Koichi FUKUDA ${ }^{2)}$ \\ 1) Graduate School of Engineering, Tohoku University, 6-6-07, Aoba, Aramaki, Aoba-ku, Sendai, 980-8579 Japan. \\ 2) Environment \& Process Technology Center, Nippon Steel Corp., 20-1, Shintomi, Futtsu, 293-8511 Japan.
}

(Received on August 20, 2010; accepted on January 17, 2011)

\begin{abstract}
A tensile strength of a coke picked from different distance away from coke oven wall was experimentally measured to investigate the effect of carbonization process by using the diametral-compression test. Changes of the microscopic structure of the coke picked from different distance away from coke oven wall were also observed to evaluate the effect of those on coke strength. The tensile strength of the coke vertically picked from the distance of 0-60 mm away from coke oven wall was higher than one picked from the distance of 60-120 mm away from coke oven wall. The microscopic structure of the coke vertically picked from the distance of $0-60 \mathrm{~mm}$ from coke oven wall was more homogeneous than the one vertically picked from the distance of 60-120 mm away from coke oven wall. Furthermore, a fracture analysis using RBSM (Rigid Bodies-Spring Model) assuming diametral-compression test was carried out in order to investigate fracture behavior of the coke. Numerical results showed that the fracture started at the near center of analytical object and crack vertically propagates by shear stress and tensile stress. Strain-load curve of analytical result was in good agreement with one of experimental result. It is supposed that fracture analysis using RBSM assuming diametral-compression test can reproduce the fracture behavior of coke.
\end{abstract}

KEY WORDS: coke strength; microscopic structure; RBSM (Rigid Bodies-Spring Model); fracture.

\section{Introduction}

Since demand for steel in Asia like China and India is increasing and it causes the rapid rise in coal price, the price of metallurgical coke also rises. Therefore, it is necessary to improve production and utilize slightly caking coal with low price. Coke's roles are very important to achieve a low reducing agent rate and high productivity in the blast furnace operation. In particular, sustaining the flow passes of liquid metal and high temperature reducing gas in the blast furnace is the most important for stable operation of blast furnaces.

The coke has many cracks and pores. It is significant to consider many strength factors to estimate strength development mechanism of the coke. However, it is difficult to clarify the effect of pore shape and crack on coke strength since drum strength tests of the coke such as drum test and tumbler test which are generally used to evaluate coke strength cannot quantitatively estimate the fracture behavior. This is the reason why it is necessary to estimate coke strength factors by using the method based on mechanics of materials.

A diametral-compression test which is used to measure a tensile strength of a concrete is proposed as one of the methods of coke strength evaluation based on mechanics of material. ${ }^{1-4)}$ In the diametral-compression test, when a cylindrical specimen is diametrically compressed between two flat plates, tensile stress is developed along the direction normal to load and causes the fracture along the diametral plane between loading parts. It is possible to measure tensile strengths of brittle materials such as concrete and coke by using this test. Patrick et al. ${ }^{1)}$ introduced diametralcompression test to measure the tensile strength of the coke. They reported the relationship between the apparent density and the tensile strength of the coke. Miyagawa et al. ${ }^{2)}$ measured the tensile strength of formed coke and investigated the relationship between the tensile strength and the binder.

The coke is porous material which consists of matrix and pore. It is known that microscopic structure which consists of matrix and pore influences coke strength. ${ }^{5,6)}$ However, there are few reports about the relationship between microscopic structure and macro strength of the coke. In carbonization process, considering the coking in direction which is normal to heated wall of coke oven, it is known that cokes picked from different distance away from coke oven wall are different in strength. ${ }^{7)}$ However, there are also few reports about the effect of changes of the microscopic structure of the coke picked from different distance away from coke oven wall on coke strength.

The coke strength is recently estimated by numerical analysis based on mechanics of materials. The relationship between the microscopic structure and the coke strength is investigated quantitatively. In previous studies, stress analyses $^{8-11)}$ using finite element method based on continuum mechanics have been carried out for the coke strength 
evaluation mainly. However, drum index (DI) evaluates amounts of fine and lump coke which pass through various fracture processes. Therefore it is necessary to consider discontinuity behavior such as crack formation and propagation by discrete method quantitatively. A Rigid BodiesSpring Model (RBSM) developed by Kawai ${ }^{12)}$ is one of the discrete approaches. We can easily carry out progressive fracture analysis and calculate collapse load and crack propagation by one. This model is applied to brittle materials such as concrete and brittle polycrystalline solid which behave as a discontinuity when fracture happens and propagates.

In this study, the tensile strength of the coke picked from different distance away from coke oven wall was measured to investigate the effect of location in coke oven on coke strength by using the diametral-compression test. Changes of the microscopic structure of each coke were also observed to evaluate the effect of those on coke strength. Furthermore, as fundamental research, we carried out fracture analysis using RBSM assuming diametral-compression test to investigate fracture behavior of coke in this test from macro viewpoint.

\section{Experiment}

\subsection{Coke Specimens}

Table 1 shows manufacturing conditions of the coke. The coke was made from the caking coal (Goonyella coal) in an electrically heated pilot coke oven (420 mm width, 600 length and $400 \mathrm{~mm}$ height). ${ }^{13)}$ A lump of coke was cut parallel to heated wall at intervals of $60 \mathrm{~mm}$. The coke picked from the distance of $0-60 \mathrm{~mm}$ away from heated wall is defined as the head part and one picked from the distance of $60-120 \mathrm{~mm}$ away from heated wall is defined as the body part.

\subsection{Measurement Principle and Condition}

\subsubsection{Diametral-Compression Test}

In the diametral-compression test, a compressive load is applied across a diameter of the specimen until the fracture of the specimen occurs along this diameter as a result of the internal tensile stress. The tensile stress is given by:

$$
\sigma=\frac{2 P}{\pi d l}
$$

where $d$ is diameter of specimen, $l$ is thickness of specimen, $P$ is load and $\sigma$ is tensile stress. In this study, tensile strength $F_{t}$ is defined as tensile stress $\sigma$ at the time when specimens break. The head and body parts of the coke were cut to the diameter of $18 \mathrm{~mm}$ and the thickness of 5-7 $\mathrm{mm}$. Cut coke

Table 1. Coking conditions of the specimens.

\begin{tabular}{llc}
\hline Coal & & Goonyella \\
\hline Grain size & {$[\mathrm{mm}]$} & $<3(80 \%)$ \\
Moisture & {$[\%]$} & 5 \\
Bulk density of coal charge & {$\left[\mathrm{t} / \mathrm{m}^{3}\right]$} & 0.8 \\
Wall temperature & {$[\mathrm{K}]$} & 1523 \\
Coking time & {$[\mathrm{h}]$} & 18.5 \\
\hline
\end{tabular}

surface is normal to heated wall. Load was applied in a vertical direction and uniaxial strain gauge was set to center of coke surface to measure strain of direction parallel to load. Diametral-compression tests were carried out for body part 11 times and head part 9 times by using Shimadzu Autograph AG-I50 kN. The rate of application of the load was standardized at a machine-crosshead speed of $2 \mathrm{~mm} /$ min and fracture appearances were observed by high-speed camera.

It is thought that many small defects exist in brittle materials such as coke and ceramic. Cracks propagate from these defects and fracture happens. Therefore fracture strengths of brittle materials depend on defects existing in brittle materials. However, it is difficult to estimate defects existing in materials previously, so statistical probability method is used to estimate fracture strengths of brittle materials. In this study, the coke strength is statistically estimated by Weibull plot which is used to estimate the brittle material such as ceramic. In this study, cumulative failure probability $F(t)$ is calculated by using the mean rank method.

\subsubsection{Observation of Microscopic Structure of Coke}

The head and body parts of the coke were impregnated with resin and polished to observe microscopic structure. Six optical photomicrographs, each $3.00 \times 3.00 \mathrm{~mm}$ and $1236 \times$ 1236 pixels, were taken. Porosity, wall thickness and roundness were calculated from optical photomicrographs by using software for image analysis (Win Roof ver.5.01). Porosity was calculated from area ratio of coke matrix and pore. Wall thickness was calculated from drawing 15 perpendicular lines and 15 parallel ones on the microscopic images and counting the average number of pixels of coke matrix. Considering each pore area, average roundness is given by:

$$
\begin{aligned}
& \text { Average roundness }= \\
& \frac{\sum(\text { Each roundness } \times \text { Each pore area })}{\text { All pore area }} .
\end{aligned}
$$

Discriminant analysis method ${ }^{14)}$ which automatically binarizes images was applied to decide threshold of binarization. Noise rejections ${ }^{15}$ ) were also carried out by dilation and contraction for 2 pixels of boundaries of images.

\subsection{Results and Discussion}

\subsubsection{Tensile Strengths of Head and Body Part}

Figure 1 shows typical images of diametral-compression test for coke by high-speed camera. In case of the body part, the tensile fracture as shown in Fig. 1 was observed 9 times in 11 times. In case of the head part, the tensile fracture was observed 7 times in 9 times. In case tensile fracture was not observed, coke specimens collapsed before tensile fracture happened and buckling occurred due to macro crack in coke. When the coke fracture happened, it was observed that coke fines generated. This is thought to be the effect of nonadhesion grain boundaries ${ }^{16)}$ which are formed due to adhesion failure in coal particles.

Figure 2 shows an example of the relationship between displacement and load in the head and body parts of the coke. Increase or decrease in load was observed as shown in Fig. 2. The load decreases because buckling of the coke 


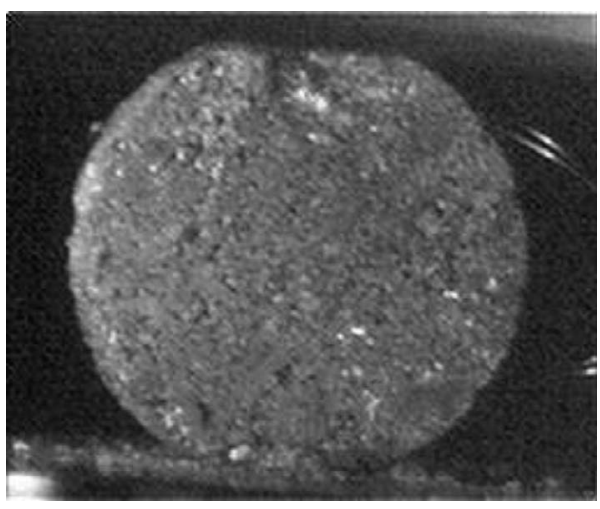

(a) Before tensile fracture

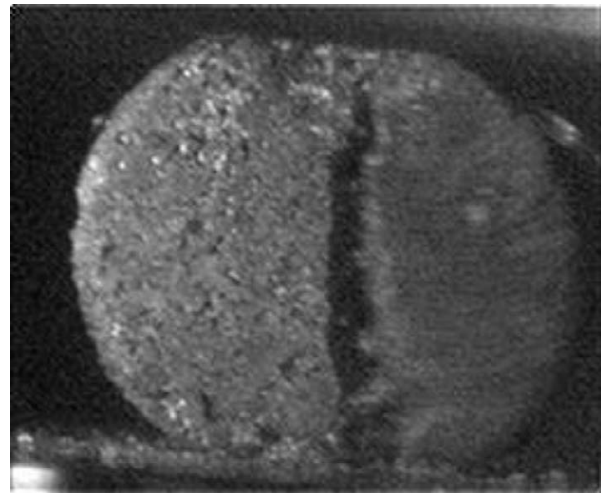

(b) After tensile fracture

Fig. 1. Images of diametral-compression test for coke by highspeed video camera.

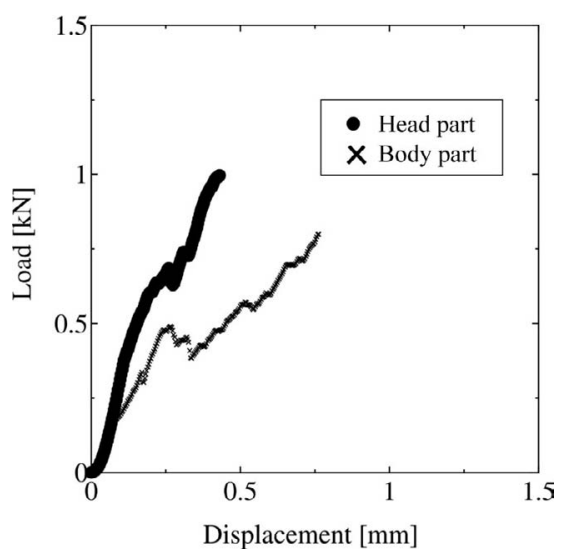

Fig. 2. Relationship between displacement and load for diametralcompression test.

at loading point occurred and microcracks were formed in the coke before fracture. The slope of the head part was steeper than that of the body part. This indicates that stiffness of the head part is higher than that of the body part.

Weibull plot was carried out in order to understand the difference between head part and body part. Figure 3 shows Weibull plot of tensile strengths of the head and body parts. Table 2 shows Weibull slope and scale parameter. If tensile fractures of the head and body parts did not occur, Weibull plot was not applied to these data. Weibull slope shows dispersion of strengths and Weibull slope is led from slope of linear regression line on Weibull plot. Scale parameter shows characteristic which 63 percent of material fractures and scale parameter is led from value of $x$-intercept of linear

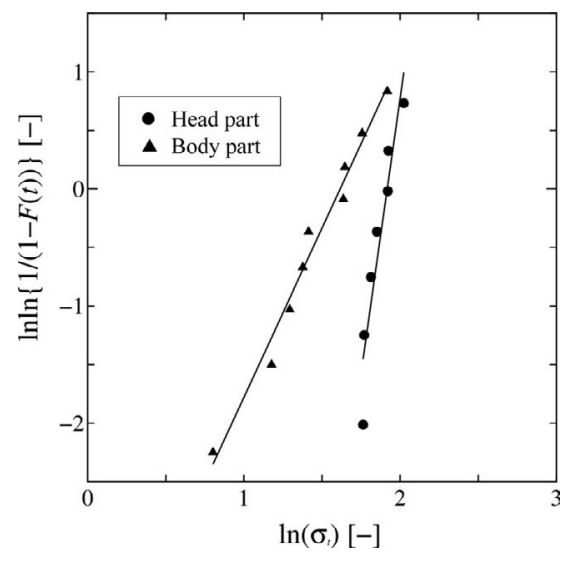

Fig. 3. Weibull plot of tensile strength.

Table 2. Weibull slopes and scale parameters from Weibull plot of tensile strength.

\begin{tabular}{llcc}
\hline & & Head & Body \\
\hline Weibull slope & {$[-]$} & 9.39 & 2.89 \\
Scale parameter & {$[\mathrm{MPa}]$} & 6.81 & 5.04 \\
\hline
\end{tabular}
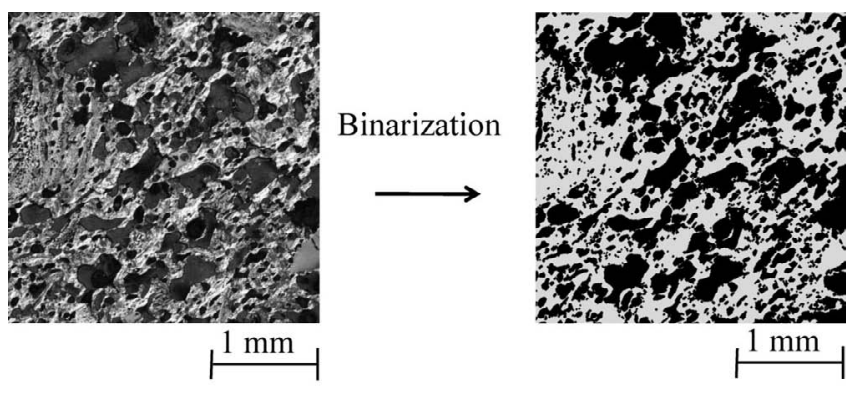

(a) Head part
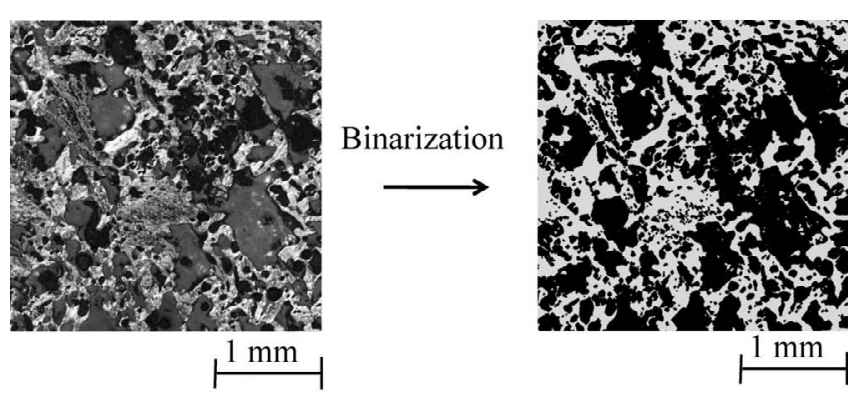

(b) Body part

Fig. 4. Optical photomicrographs of coke and their binary images.

regression line on Weibull plot. As shown in Table 2, Weibull slope and scale parameter of the head part were higher than those of the body part. This indicates that strength of the head part is higher than that of the body part and the dispersion of strength of the head part is less than that of the body part.

\subsubsection{Microscopic Structures of Head and Body Parts}

Figure 4 shows examples of optical photomicrographs and binary images of the head and body parts of the coke, respectively. Table 3 shows average values and variation coefficients of porosity, wall thickness and roundness. The variation coefficient is calculated from dividing standard 
Table 3. Average values and variation coefficients for the coke pore structure.

\begin{tabular}{llll}
\hline & & Head & Body \\
\hline Average porosity & {$[-]$} & 0.521 & 0.608 \\
$\quad$ Variation coefficient of porosity & {$[-]$} & 0.038 & 0.092 \\
Average wall thickness & {$[\mathrm{mm}]$} & 0.070 & 0.061 \\
$\quad$ Variation coefficient of wall thickness & {$[-]$} & 0.052 & 0.125 \\
Average roundness & {$[-]$} & 0.183 & 0.117 \\
$\quad$ Variation coefficient of roundness & {$[-]$} & 0.085 & 0.346 \\
\hline
\end{tabular}

deviation by arithmetic mean. In this study, it is applied as the index of dispersion. Average porosity of the head part was lower than that of the body part. Average wall thickness and roundness of the head part were higher than those of the body part. These indicate that apparent density of the head part is higher and pore shape of the head part is closer to circularity than the body part. As a result, the tensile strength of the head part is higher than that of the body part. All of variation coefficients of the head part were lower than those of body part. This indicates that the head part is more homogeneous in microscopic structure than the body part. As a result, the dispersion of strength of the head part is less than that of body part. Furthermore, variation coefficient of roundness is the highest of three parameters (porosity, wall thickness and roundness) both in head and body parts. In addition, variation coefficients of roundness are the largest difference between head part and body part in three parameters. Ueoka et al. ${ }^{8)}$ reported that coke rigidity decreases with increasing pore whose roundness is low even if average wall thickness is thin. It is suggested that roundness is important for coke strength difference between body part and head part.

Tendency of Weibull plot of tensile strength matched one of microscopic structure. It is supposed that changes of microscopic structure due to difference in distance from coke oven wall influence magnitude of strength and dispersion of strength. Changes of microscopic structure in difference of distance from coke oven wall result from thermal plasticity being improved since heating rate of the head part is higher than the body part ${ }^{17)}$ and porosity of the head part decreasing since molten substance which is produced when coal is melted at center side of the coke oven flows toward the head part. ${ }^{7)}$

\section{Fracture Analysis Using Rigid Bodies-Spring Model}

\subsection{Analytical Object and Conditions}

Rigid Bodies-Spring Model (RBSM) developed by Kawai ${ }^{12)}$ was applied to coke. In RBSM, analytical object is divided into triangle elements interconnected along their boundaries by springs. Each element has two translational and one rotational degrees of freedom defined at the element center of gravity. The interface between two elements consists of two springs. Normal and shear springs are placed at the boundary of element. Energy which is calculated from surface force between elements instead of the internal work of each element is estimated. Analytical method is reported in previous study ${ }^{18)}$ in detail.

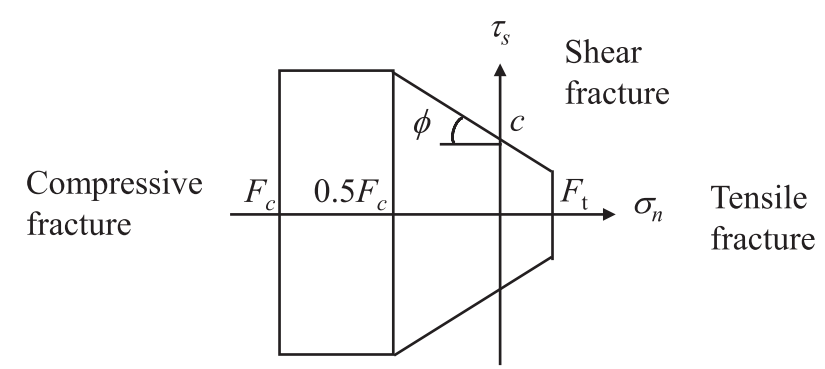

Fig. 5. Fracture criterion of analytical object in RBSM.

Table 4. Physical properties of the analytical object for diametralcompression test in RBSM.

\begin{tabular}{llc}
\hline Elastic modulus & {$[\mathrm{GPa}]$} & 4.0 \\
Poisson's ratio & {$[-]$} & 0.2 \\
Critical breakage strain for tensile direction & {$[-]$} & $6.4 \times 10^{-4}$ \\
Tensile strength & {$[\mathrm{MPa}]$} & 5.0 \\
Compressive strength & {$[\mathrm{MPa}]$} & 61.6 \\
Critical breakage strain for compressive direction & {$[-]$} & $1.1 \times 10^{-3}$ \\
Shear strength & {$[\mathrm{MPa}]$} & 8.7 \\
Internal friction angle & $\left.{ }^{\circ}\right]$ & 32.0 \\
\hline
\end{tabular}

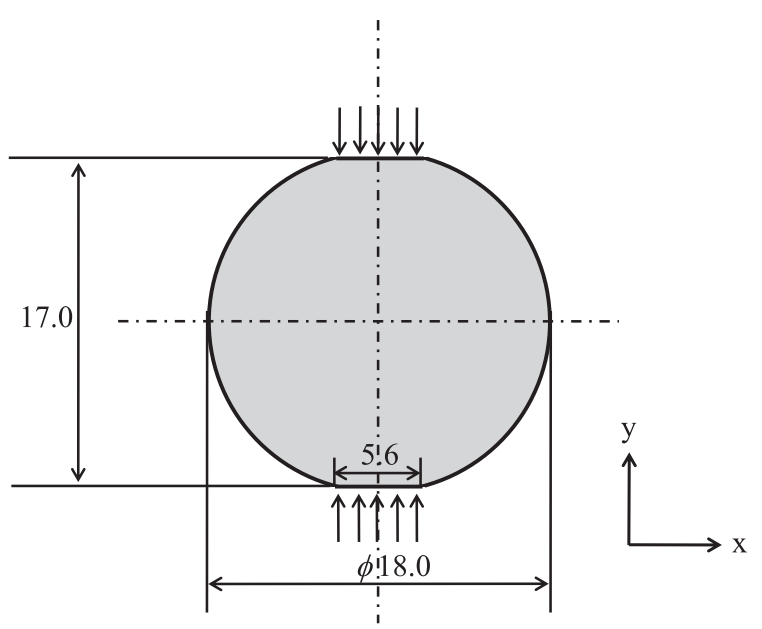

Fig. 6. Schematic diagram of analytical object for diametral-compression test at the time when top and bottom parts of specimen collapse.

Figure 5 shows fracture criterion. The fracture analysis with RBSM assuming diametral-compression test was carried out. Table 4 shows material properties. ${ }^{19,20)}$ In this study, coke was assumed to be homogeneous material which consists of matrix and pore. Since shear strength $c$ of coke has not been clarified, the following approximate equation ${ }^{21)}$ of the shear strength for brittle materials like glasses and rocks was applied as:

$$
c=3^{0.5} F_{t},
$$

where $c$ is shear strength and $F_{t}$ is tensile strength.

Figure 6 shows analytical object. Triangle elements were applied and the number of meshes was 2244. In the diametral-compression tests, about 5 percent of diameter of specimen collapsed at contact point between specimen and plate before tensile fracture happened, so in this study, 5 percent of diameter of specimen ( 2.5 percents of top and bottom 


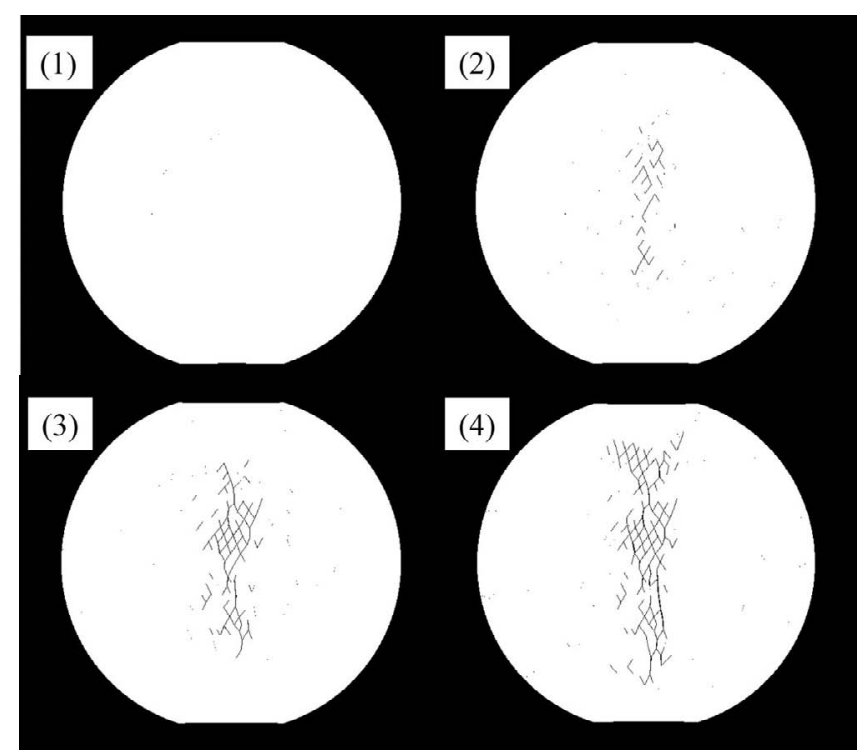

Fig. 7. Calculation of crack propagation by RBSM ; The loads are $44 \mathrm{~N}$ in (1), $935 \mathrm{~N}$ in (2), $967 \mathrm{~N}$ in (3) and $1005 \mathrm{~N}$ in (4), respectively. Gray line: shear fracture, Black line: tensile fracture.

parts, respectively) was cut as shown in Fig. 6.

\subsection{Results and Discussion}

\subsubsection{Fracture Appearances}

Figure 7 shows calculation result of crack propagation in diametral-compression test by RBSM. In Fig. 7, gray and black line show shear and tensile fracture, respectively. The load increases in the order of the number in Fig. 7. As shown in Fig. 7, tensile fracture happened at the near center of analytical object and cracks propagated vertically upward and downward. In the experiment, fracture happened along the direction normal to load by tensile stress as shown in Fig. 1. In the numerical result, tensile fracture also occurred along the same direction as experiment as shown in Fig. 7 (4). As a result, we can reproduce fracture appearances in diametral-compression test by using RBSM.

Figure 8 shows stress distribution of $x$ direction which is normal to load. The number of Fig. 8 corresponds to the number of Fig. 7. Minus and plus values represent compressive and tensile stress, respectively. As shown in Fig. 8, stress concentration occurred at top and bottom parts. Compressive stress at top and bottom parts is higher than tensile stress at center of coke. However, brittle material such as coke is generally higher compressive strength than tensile and shear strengths. Therefore fracture happens by tensile and shear stress. ${ }^{2)}$

\subsubsection{Strain-load Curve of Coke}

Figure 9 shows strain-load curve, whose direction is normal to load, of calculation and experiment of the head part coke. Strain is obtained from result of strain gauge in experiment and calculated from displacement of center of analytical object in RBSM, respectively. In the experiment, load showed constant value after load reached the maximum load and coke yielded. This is because strain gauge broke since fracture happened at the point where strain gauge was set when load reached the maximum load. In this analysis,
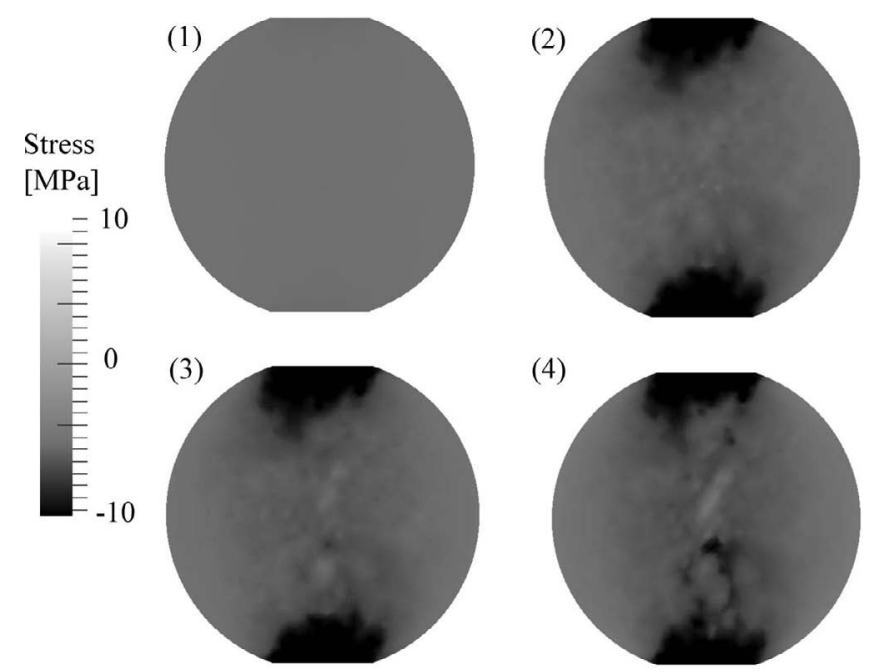

Fig. 8. Stress distribution of analytical object for diametral-compression test in the $x$ direction; The number of Fig. 8 corresponds to the number of Fig. 7.

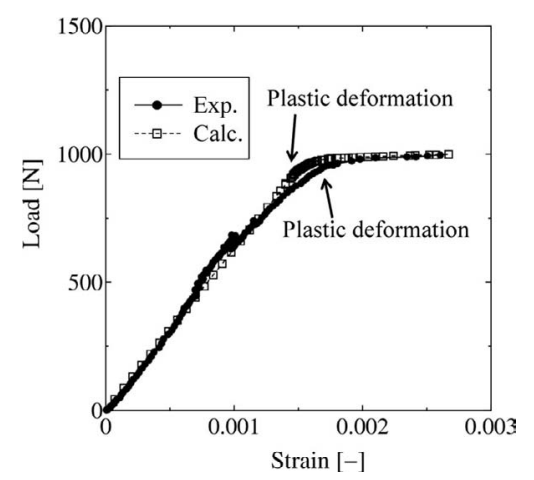

Fig. 9. Horizontal strain-load curve of calculation and experiment of the head partcoke.

strain after yield was represented like experimental results. As shown in Fig. 9, fracture rapidly happened after plastic deformation happened and analytical results reproduced brittle fracture behavior well. It is indicated that the fracture analysis using RBSM can reproduce diametral-compression test.

In this study, coke was assumed to be homogeneous material which consists of matrix and pore. We carried out fracture analysis from macro viewpoint. However, it is necessary to carry out fracture analyses considering microscopic structure of coke such as pore shape and internal failure. In the future, we are going to carry out fracture analysis from micro viewpoint based on microscopic image of coke. ${ }^{22)}$ It is thought that we can quantitatively estimate difference between the head and body parts of the coke by carrying out fracture analysis of coke microstructure directly based on microscopic image of coke.

\section{Conclusions}

In this study, the tensile strength of the coke picked from different distance away from coke oven wall was measured to investigate the effect of carbonization process by using the diametral-compression test. Changes of the microscopic structure of the different coke were also observed to evalu- 
ate the effect of those for the coke strength. Furthermore, as fundamental research, we carried out fracture analysis using RBSM assuming diametral-compression test to investigate fracture behavior of coke in this test from macro viewpoint.

The conclusions are summarized as follows.

(1) The tensile strength of the head part of coke is higher than that of the body part. Dispersion of the strength of the head part is less than the body part. Furthermore, it is supposed that magnitude of strength and dispersion of strength are concerned with microscopic structure from observation of one.

(2) Fracture analysis using RBSM assuming diametralcompression test reproduces fracture behavior of coke and can represent fracture propagation of diametral-compression test.

\section{Acknowledgements}

This work has been done in Research Group of Process Technology Making High-Strength and High-Reactivity Coke in ISIJ (The chief examiner: Prof. K. Miura, Kyoto Univ.). The authors would like to acknowledge the research group members gratefully.

\section{Nomenclature}

$c$ : shear strength

$[\mathrm{MPa}]$

$d$ : diameter of specimens

$F_{c}$ : compressive strength

$[\mathrm{MPa}]$

$F_{t}$ : tensile strength

$F(t)$ : cumulative failure probability

$[\mathrm{MPa}]$

$l$ : thickness of specimens

$P$ : load

$\phi$ : internal friction angle $\sigma:$ tensile stress

$\sigma_{n}:$ normal stress

$\tau_{s}:$ shear stress

\section{REFERENCES}

1) J. W. Patrick and A. E. Stacey: Fuel, 51 (1972), 81.

2) T. Miyagawa and I. Fujishima: J. Fuel Soc. Jpn., 54 (1975), 983.

3) M. Kawakami, K. Murayama, M. Shibata, T. Takenaka and H. Toda: Tetsu-to-Hagané, 87 (2001), 252.

4) T. Kamijo, H. Iwakiri, J. Kiguchi, T. Yabata, H. Tanaka and M. Kitamura: Tetsu-to-Hagané, 73 (1987), 2012.

5) T. Arima: Tetsu-to-Hagané, 87 (2001), 274.

6) Y. Kubota, S. Nomura, T. Arima and K. Kato: ISIJ Int., 48 (2008), 563.

7) K. Nishioka and S. Yoshida: Tetsu-to-Hagané, 70 (1984), 351.

8) K. Ueoka, T. Ogata, Y. Matsushita, H. Aoki, T. Miura, K. Fukuda and K. Matsudaira: Tetsu-to-Hagané, 93 (2007), 728

9) Y. Asakuma, M. Soejima, T. Yamamoto, H. Aoki, T. Miura and S. Itagaki: Tetsu-to-Hagané, 87 (2001), 685.

10) Y. Asakuma, M. Soejima, T. Yamamoto, H. Aoki and T. Miura: ISIJ Int., 43 (2003), 1151.

11) M. Soejima, Y. Asakuma, T. Mori, T. Yamamoto, H. Aoki, T. Miura, S. Tanioka and S. Itagaki: Tetsu-to-Hagané, 87 (2001), 245.

12) T. Kawai: J. Soc. Naval Arch. Japan, 141 (1977), 187.

13) S. Nomura, T. Arima and K. Kato: Fuel, 83 (2004), 1771.

14) N. Otsu: Trans. Inst. Electron. Commun. Eng. Jpn., 63D (1980), 349.

15) Y. Nagano, Y. Ikeda, H. Kawamoto and N. Takano: J. JSNDI, 53 (2004), 701.

16) T. Arima: Tetsu-to-Hagané, 92 (2006), 106.

17) K. Fukada, S. Itagaki and I. Shimoyama: ISIJ Int., 46 (2006), 1603.

18) K. Hiraki, H. Hayashizaki, T. Ogata, Y. Yoshiaki, Y. Matsushita, H. Aoki, T. Miura, K. Fukuda and K. Matsudaira: Tetsu-to-Hagané, 96 (2010), 313.

19) K. Katayama, S. Wakabayashi, T. Inada, K. Takatani and H. Yamaoka: Tetsu-to-Hagané, 83 (1997), 91.

20) M. Isobe, K. Suzuki, M. Take and H. Kitagawa: Tetsu-to-Hagané, 66 (1980), 307.

21) The Society of Chemical Engineers: Handbook of Chemical Engineers 6th Edition, Maruzen, Tokyo (1999), 270
22) H. Hayashizaki, K. Ueoka, M. Kajiyama, Y. Yamazaki, K. Hiraki, Y. Matsushita, H. Aoki, T. Miura, K. Fukuda and K. Matsudaira: Tetsu- to-Hagané, 95 (2009), 593.

